\title{
Decreasing the number of small eating occasions ( $<15 \%$ of total energy intake) regardless of the time of day may be important to improve diet quality but not adiposity: a cross-sectional study in British children and adolescents
}

\author{
Kentaro Murakami ${ }^{1 *}$ and M. Barbara E. Livingstone ${ }^{2}$ \\ ${ }^{1}$ Department of Nutrition, School of Human Cultures, University of Shiga Prefecture, Shiga, Hikone, Shiga 522 8533, Japan \\ ${ }^{2}$ Northern Ireland Centre for Food and Health, Ulster University, Coleraine BT52 1SA, UK \\ (Submitted 16 June 2015 - Final revision received 29 September 2015 - Accepted 8 October 2015 - First published online 16 November 2015)
}

\section{Abstract}

Evidence of associations between meal frequency (MF) and snack frequency (SF) and diet and obesity in young populations is limited. This cross-sectional study examined MF and SF in relation to dietary intake and adiposity measures in British children aged 4-10 years ( $n$ 818) and adolescents aged 11-18 years ( $n$ 818). Based on data from a 7-d weighed dietary record, all eating occasions were divided into meals or snacks on the basis of contribution to energy intake ( $\geq 15$ or $<15 \%)$ or time (06.00-10.00, 12.00-15.00 and 18.00-21.00 hours or others). All measures of MF and SF showed positive associations with energy intake, except for MF based on energy contribution in children. Irrespective of the definition of snacks, SF was associated with higher intakes of soft drinks, confectionery and total sugar, lower intakes of cereals, fish, meat, protein, PUFA, starch and dietary fibre, and a lower diet quality (assessed by the Mediterranean diet score, except for SF based on energy contribution in adolescents). MF based on time, but not based on energy contribution, was associated with higher intakes of confectionery and total sugar, lower intakes of fish, protein, PUFA and starch, and, only in children, a lower diet quality. All measures of MF and SF showed no association with adiposity measures. In conclusion, this cross-sectional study in British children and adolescents suggests that decreasing the number of small eating occasions ( $<15 \%$ of total energy intake) regardless of the time of day may be important to improve diet quality but not adiposity.

\section{Key words: Meal frequency: Snack frequency: Children: Adolescents}

Many epidemiological studies conducted in children and adolescents have shown an inverse association between eating frequency (EF) and adiposity measures ${ }^{(1-14)}$, with some exceptions $^{(15-20)}$. However, these results should be interpreted with caution given the methodological limitations associated with these studies. First, although the assessment of EF has often relied on a series of non-validated, self-report questions $^{(3,4,7-11,13,17)}$, only a few studies have assessed EF on the basis of information on actual dietary habits (using dietary record or 24-h recall) ${ }^{(1,12,15,20)}$. Second, the association of EF with adiposity measures may be confounded by possible under-reporting of EF concomitant with the under-reporting of energy intake (EI) by obese or overweight subjects ${ }^{(21,22)}$. For example, one study found that when subjects with implausible EI were eliminated from the analytic sample, the inverse relation between EF and BMI percentile no longer existed among children and adolescents ${ }^{(19)}$. Third, interpreting the literature on $\mathrm{EF}$ is complicated by the fact that there is no consensus about what constitutes a snack, a meal or an eating occasion. Although some researchers have relied on respondents' self-identification of meals, snacks or eating occasions ${ }^{(2-4,7-13,17,18)}$, others have attempted to use more objective criteria ${ }^{(1,14-16,19,20)}$ to overcome concerns over definitional differences. More importantly, potentially different effects of meal frequency (MF) and snack frequency (SF) have not been investigated simultaneously using different definitions of meals and snacks. Further, investigation of the association between MF and SF and dietary intake is extremely limited $^{(23)}$. As a consequence of these methodological limitations, the discrepant findings are not surprising, which clearly bring into question the direction of the relationship of MF and SF with diet quality and adiposity measures and whether a relationship even exists.

An accurate distinction between meals and snacks is important, because they are hypothesised to have opposite effects on energy balance. A high MF may prevent fat mass deposition, whereas snacking may contribute to it ${ }^{(24)}$. This is also important

Abbreviations: EER, estimated energy requirement; $\mathrm{EF}$, eating frequency; $\mathrm{EI}$, energy intake; MDS, Mediterranean diet score; $\mathrm{MF}$, meal frequency; $\mathrm{MF}$ energy\%, $\mathrm{MF}$ determined based on percentage contribution to total EI; MF $\mathrm{M}_{\text {time, }}$, MF determined based on the time consumed; NDNS, National Diet and Nutrition Survey; SF, snack frequency; $\mathrm{SF}_{\text {energy\%, }} \mathrm{SF}$ determined based on percentage contribution to total $\mathrm{EI}$; $\mathrm{SF}$ time, $\mathrm{SF}$ determined based on the time consumed; WHtR, waist:height ratio.

* Corresponding author: Dr K. Murakami, fax +81 74949 8499, email kenmrkm@m.u-tokyo.ac.jp 
for the development of science-based recommendations (of snacking) for consumers ${ }^{(25)}$. Moreover, in the absence of a universally accepted definition of meals and snacks, an understanding of the influence of different meal and snack definitions on the associations with diet quality and adiposity may facilitate the interpretation of the existing literature and help establish consensus on the most appropriate research definition for meals and snacks ${ }^{(26)}$

Therefore, the primary aim of the present cross-sectional study was to examine the relationship of MF and SF with food and nutrient intakes, diet quality and adiposity measures in British children and adolescents, by using different definitions of meals and snacks. The secondary aim was to examine the impact of exclusion of misreporters of EI on these associations.

\section{Methods}

\section{Survey design}

The present cross-sectional study was based on data from the National Diet and Nutrition Survey (NDNS): Young People Aged 4 to 18 Years. Data from the NDNS were obtained from the UK Data Archive, University of Essex. Full details of the rationale, design and methods of the survey have been described elsewhere ${ }^{(27,28)}$. Briefly, the sample was randomly selected from 132 randomly selected postal sectors within mainland Great Britain. Eligibility was defined as being aged 4-18 years. One eligible person per private household was selected at random. Data collection was conducted during a 12-month period (January to December 1997). This study was conducted according to the guidelines laid down in the Declaration of Helsinki, and all procedures involving human subjects were approved by the National Health Service Local Research Ethics Committee covering each of the postal sectors. A verbal informed consent was obtained from all subjects and their parents/guardians. Verbal consent was witnessed and formally recorded.

\section{Anthropometric measurements}

All anthropometric measurements were performed in duplicate by trained fieldworkers, and the mean value of two measurements was used in the analysis. Height (to the nearest $0.1 \mathrm{~cm}$ ) and weight (to the nearest $0 \cdot 1 \mathrm{~kg}$ ) were measured while subjects were barefoot and wearing only light clothes. BMI $\left(\mathrm{kg} / \mathrm{m}^{2}\right)$ was calculated as weight $(\mathrm{kg})$ divided by height squared $\left(\mathrm{m}^{2}\right)$ and converted age- and sex-specific $z$ score according to British growth-reference data ${ }^{(29)}$. For subjects aged $\geq 11$ years, waist circumference was also measured at the midpoint between the iliac crest and the lower rib (to the nearest $0 \cdot 1 \mathrm{~cm}$ ). Waist:height ratio (WHtR) was calculated as waist circumference divided by height.

\section{Dietary assessment}

Dietary data were collected through a 7-d weighed dietary record. A detailed description of the procedure has been published elsewhere ${ }^{(27,28)}$. Briefly, the subject, the parent or both, depending on the age of the subject, were asked to keep a weighed record of all food and drinks consumed by the subject, both in and out of the home, over 7 consecutive days. They were supplied with a set of digital food scales and recording diaries and given by trained interviewers both written and verbal instructions on how to weigh and record items in the diary. When weighing was not possible (e.g. eating out), the subject was asked to record as much information as possible. Generally, children aged 10 years and over were able to complete the diary themselves, whereas for children aged $<10$ years the parent/guardian was expected to complete the diary. Trained interviewers visited the household at least twice during the recording period and checked the completeness of food recording. All the collected diaries were checked by trained nutritionists in terms of coding, recorded weights and descriptions of items consumed. Estimates of daily intake for foods, energy and selected nutrients were calculated on the basis of the Food Standards Agency nutrient databank ${ }^{(30)}$, which is based on McCance and Widdowson's composition of foods series $^{(31)}$, and manufactures' data where applicable. For all dietary variables, mean daily values over $7 \mathrm{~d}$ were used in the analysis. Values of food and nutrient intake were energyadjusted using the density method (i.e. percentage of energy for energy-providing nutrients and amount per $10 \mathrm{MJ}$ of energy for foods and other nutrients).

As a measure of diet quality, the Mediterranean diet score (MDS) was calculated. The MDS represents a Mediterraneantype diet and is based on the consumption of eight different components (vegetables, legumes, fruits, cereals, fish, the ratio of unsaturated fatty acid:SFA, meat and dairy products) ${ }^{(32,33)}$. To modify the score for children and adolescents, the alcohol consumption component was removed from the score. For each component, subjects with an intake (g/10 MJ) above or equal to the age group- and sex-specific median were assigned a score of 1 (a score of 0 to those below), except for meat and dairy products, for which the score was assigned in the reverse manner. Scores for all eight components were summed and resulted in a total range from 0 to 8 , whereby a higher score reflected better adherence to a Mediterranean-type diet.

\section{Definition of eating frequency, meal frequency and snack frequency}

Data from the 7-d dietary record were also used to calculate the mean number of eating occasions per day, that is, EF. Eating occasions were defined as any occasion when any food or drink was consumed $^{(1,12,14,16,20,34-36)}$. If two eating occasions occurred in $\leq 15 \mathrm{~min}$, both events were counted as a single eating occasion, and when $>15$ min separated two eating occasions, these were considered distinct eating occasions ${ }^{(14,15,20,36,37)}$. EF was calculated on the basis of all eating occasions except for those providing $<210 \mathrm{~kJ}$ of energy. This calculation method has been used in several previous studies ${ }^{(20,34,38)}$ and was chosen to avoid giving undue weight to eating occasions that only included water, low-energy beverages or small quantities of foods.

All eating occasions were divided into either meals or snacks with the use of two different published definitions: on the basis of (1) contribution to total $\mathrm{EI}^{(1)}$ and (2) clock time ${ }^{(39)}$. For the 
first definition ${ }^{(1)}$, a meal was defined as any eating episode comprising $\geq 15 \%$ of total EI, regardless of the time of day or composition of foods or beverages consumed. All other eating episodes were classified as a snack. For each participant, MF and SF determined on the basis of EI contribution were calculated (hereafter referred to as $\mathrm{MF}_{\text {energy\% }}$ and $\mathrm{SF}_{\text {energy\%, }}$ respectively). For the second definition ${ }^{(39)}$, meals were defined as eating events reported during selected times of the day, that is, 06.00-10.00, $12.00-15.00$ and 18.00-21.00 hours. All other eating occasions were considered snacks. For each participant, MF and SF determined on the basis of time were calculated (hereafter referred to as $\mathrm{MF}_{\text {time }}$ and $\mathrm{SF}_{\text {time, }}$ respectively).

\section{Assessment of non-dietary variables}

The socio-economic status of head of household (i.e. occupational social class) was reported and used as a proxy for children's social class. The following three categories were used: manual (i.e. skilled manual, partly skilled and unskilled occupations: social classes III manual, IV and V), non-manual (i.e. professional, managerial, technical and skilled non-manual occupations: social classes I, II and III non-manual) or unclassified.

For subjects aged $\geq 7$ years, a 7 -d physical activity diary was completed concurrently with the dietary record. A detailed description of the procedure has been published elsewhere ${ }^{(27,28)}$. Briefly, the subject was asked to provide information on the time spent being active from a list of prompted moderate, vigorous and very vigorous activities. Information on activities that were not already listed and sleep was also provided. Trained interviewers checked the completeness of records at least twice during the recording period. Subsequently, time spent daily in sleep, very light, light, moderate, vigorous and very vigorousintensity activities was computed for each day of recording. The number of hours spent per day on each activity was multiplied by the metabolic equivalent value of that activity (derived from a published table) ${ }^{(40)}$, and all metabolic equivalent-h products were summed to produce a total metabolic equivalent-h score for the day. They were then divided by $24 \mathrm{~h}$ to give a physical activity level value, and classified into four categories (sedentary, low active, active and very active) according to the US Dietary Reference Intakes ${ }^{(41)}$. For subjects aged $\leq 6$ years, for which the activity diary was not collected, the 'active' level was assigned on the basis of a result on total energy expenditure measured using the doubly labelled water in the NDNS feasibility study ${ }^{(42)}$.

\section{Evaluation of energy intake reporting}

We calculated each subject's estimated energy requirement (EER) with the use of equations published in the US Dietary Reference Intakes ${ }^{(41)}$. Subjects were identified as acceptable reporters, under-reporters or over-reporters of EI on the basis of their ratio of EI:EER, according to whether the individual's ratio was within, below or above the $95 \%$ confidence limits of the expected ratio of $1 \cdot 0$. On the basis of a published equation ${ }^{(19)}$, acceptable reporters were defined as having EI:EER in the range $0 \cdot 72-1 \cdot 28$, under-reporters as EI:EER $<0.72$ and over-reporters as EI:EER $>1 \cdot 28$. A detailed description of the procedure has been published elsewhere ${ }^{(28)}$.

\section{Analytic sample}

Of 2672 potentially eligible people identified for the study, 2127 ( $80 \%$ of the eligible sample) participated in the survey. For the present analysis, we excluded a total of 443 subjects with missing information on the variables used ( $n 182$ for anthropometric data, $n 426$ for dietary data, $n 125$ for physical activity data, and some subjects had more than one missing value). We further excluded forty-eight underweight subjects (i.e. BMI $\leq 3 \mathrm{rd}$ percentile of the age- and sex-specific growth-reference data $\left.{ }^{(29)}\right)$. The final analysis sample comprised 1636 subjects aged 4-18 years ( $61 \%$ of the eligible sample).

\section{Statistical analysis}

All statistical analyses were performed for children aged 4-10 years and adolescents aged 11-18 years separately, using SAS statistical software (version 9.2; SAS Institute Inc.). Separate analyses for boys and girls showed similar patterns of associations, and tests for interaction with sex were not significant (data not shown). We therefore present results for both sexes combined. Associations among various measures of MF and SF were investigated through Pearson's correlation analyses. Associations of MF and SF with intakes of energy and selected foods and nutrients and MDS were investigated by linear regression analyses using PROC REG procedure. Linear regression analyses were also performed to explore the associations of MF and SF with BMI $z$ score and WHtR. With the use of the PROC REG procedure, we calculated the adjusted regression coefficients with their standard errors of variation of BMI $z$ score and WHtR by one increase of MF and SF. Potential confounding factors considered were age, sex, social class and physical activity. In adolescents, we further included EI:EER as a potential confounding factor, because EI:EER was associated not only with BMI $z$ score (Pearson's $r-0.24$ ) and WHtR (Pearson's $r-0 \cdot 13$ ) but also with all measures of MF and SF (Pearson's $r 0 \cdot 15-0 \cdot 49$ ) (all $P \leq 0 \cdot 0002$ ). This approach has been used in several previous studies ${ }^{(16,20,28,43-45)}$. EI was not included as a potential confounding factor not only because we considered EI as a potential causal pathway between MF and SF and adiposity measures but also because there was a strong correlation between EI and EI:EER (Pearson's $r$ 0.73). MF and SF were analysed continuously after confirming the linearity of relations using tertile, quartile and quintile categories. The analyses were conducted not only for the entire population but also for acceptable reporters.

Data have not been weighted to take into account known socio-demographic differences between responders and nonresponders not only because the impact of this adjustment applied as a weighting factor - for nutritional variables was extremely small and not significant ${ }^{(27)}$ but also because we were only interested in relationships between variables, rather than estimates of prevalence ${ }^{(20,28)}$. All reported $P$ values are two-tailed, and $P$ values of $<0 \cdot 01$ were considered statistically significant to minimise the chance of a type 1 error arising from multiple testing. 


\section{Results}

The mean value of BMI $z$ score was 0.38 in children and 0.47 in adolescents (Table 1). Under-reporting of EI compared with EER was on average $16 \%$ in children and $30 \%$ in adolescents. The percentages of acceptable reporters and under-reporters were 80 and $19 \%$ in children and 47 and $52 \%$ in adolescents, respectively (only six children $(0.7 \%)$ and three adolescents $(0.4 \%)$ were classified as over-reporters).

The mean values of $\mathrm{MF}_{\text {energy\% }}$ and $\mathrm{MF}_{\text {time }}$ were, respectively, 2.57 and 3.39 times/d in children and 2.47 and 3.03 times/d in adolescents (Table 2). Although there was no correlation between $\mathrm{MF}_{\text {energy\% }}$ and $\mathrm{MF}_{\text {time }}$ in children, $\mathrm{MF}_{\text {energy\% }}$ was weakly correlated with $\mathrm{MF}_{\text {time }}$ in adolescents. The mean values of $\mathrm{SF}_{\text {energy\% }}$ and $\mathrm{SF}_{\text {time }}$ were, respectively, 2.36 and 1.54 times/d in children and 2.18 and 1.62 times/d in adolescents. There were moderate correlations between two measures of SF in both children and adolescents. While $\mathrm{MF}_{\text {energy\% }}$ showed a weak inverse correlation with $\mathrm{EF}$ in children and a weak positive correlation with $\mathrm{EF}$ in adolescents, there were strong correlations of $\mathrm{MF}_{\text {time, }}, \mathrm{SF}_{\text {energy\% }}$ and $\mathrm{SF}_{\text {time }}$ with $\mathrm{EF}$ in both age groups.

In children, there were no associations between $\mathrm{MF}_{\text {energy\% }}$ and any of the dietary characteristics examined (Table 3). However, $\mathrm{MF}_{\text {time }}, \mathrm{SF}_{\text {energy\%}}, \mathrm{SF}_{\text {time }}$ and $\mathrm{EF}$ were associated positively with intakes of energy, dairy products, confectionery and soft drinks (except for $\mathrm{MF}_{\text {time}}$ ) and inversely with legumes, cereals, fish and meat. There were inverse associations of $\mathrm{SF}_{\text {time }}$ and $\mathrm{EF}$ with vegetables. For nutrient intake, $\mathrm{MF}_{\text {time }}, \mathrm{SF}_{\text {energy\%, }}$ $\mathrm{SF}_{\text {time }}$ and $\mathrm{EF}$ were associated positively with SFA and total sugar and inversely with protein, PUFA, starch and dietary fibre. There was a positive association between $\mathrm{SF}_{\text {time }}$ and carbohydrate. $\mathrm{MF}_{\text {time }}, \mathrm{SF}_{\text {energy\%}}, \mathrm{SF}_{\text {time }}$ and $\mathrm{EF}$ also showed inverse associations with MDS.

In adolescents, all measures of MF, SF and EF were positively associated with intakes of energy and carbohydrate and inversely with intakes of meat and MUFA (Table 4). $\mathrm{MF}_{\text {time, }}, \mathrm{SF}_{\text {energy\%, }} \mathrm{SF}_{\text {time }}$

Table 1. Characteristics of subjects

(Mean values and standard deviations; percentages)

\begin{tabular}{|c|c|c|c|c|}
\hline & \multicolumn{2}{|c|}{$\begin{array}{c}\text { Children aged } \\
4-10 \text { years }(n \text { 818) }\end{array}$} & \multicolumn{2}{|c|}{$\begin{array}{l}\text { Adolescents aged } \\
11-18 \text { years }(n 818)\end{array}$} \\
\hline & Mean & SD & Mean & SD \\
\hline Age (years) & $7 \cdot 1$ & 1.9 & $14 \cdot 2$ & $2 \cdot 3$ \\
\hline Sex (\% boys) & \multicolumn{2}{|c|}{53.2} & \multicolumn{2}{|c|}{$48 \cdot 6$} \\
\hline \multicolumn{5}{|l|}{ Social class (\%) } \\
\hline Manual & \multicolumn{2}{|c|}{$42 \cdot 9$} & \multicolumn{2}{|c|}{$45 \cdot 1$} \\
\hline Non-manual & \multicolumn{2}{|c|}{49.4} & \multicolumn{2}{|c|}{$46 \cdot 3$} \\
\hline Unclassified & \multicolumn{2}{|c|}{$7 \cdot 7$} & \multicolumn{2}{|c|}{8.7} \\
\hline \multicolumn{5}{|c|}{ Physical activity (\%)* } \\
\hline Low active & \multirow{2}{*}{\multicolumn{2}{|c|}{$\begin{array}{r}5.6 \\
87.4\end{array}$}} & \multicolumn{2}{|c|}{$6 \cdot 4$} \\
\hline Active & \multirow{2}{*}{\multicolumn{2}{|c|}{$\begin{array}{r}87.4 \\
7.0\end{array}$}} & \multirow{2}{*}{\multicolumn{2}{|c|}{$\begin{array}{l}75.2 \\
18.4\end{array}$}} \\
\hline Very active & & & & \\
\hline BMI $z$ score & 0.38 & 0.98 & 0.47 & 1.06 \\
\hline WHtR & - & - & 0.46 & 0.06 \\
\hline El:EER & 0.84 & 0.16 & 0.70 & 0.18 \\
\hline
\end{tabular}

WHtR, waist:height ratio; El:EER, ratio of energy intake to estimated energy requirement.

* There were no subjects classified into 'sedentary' level.

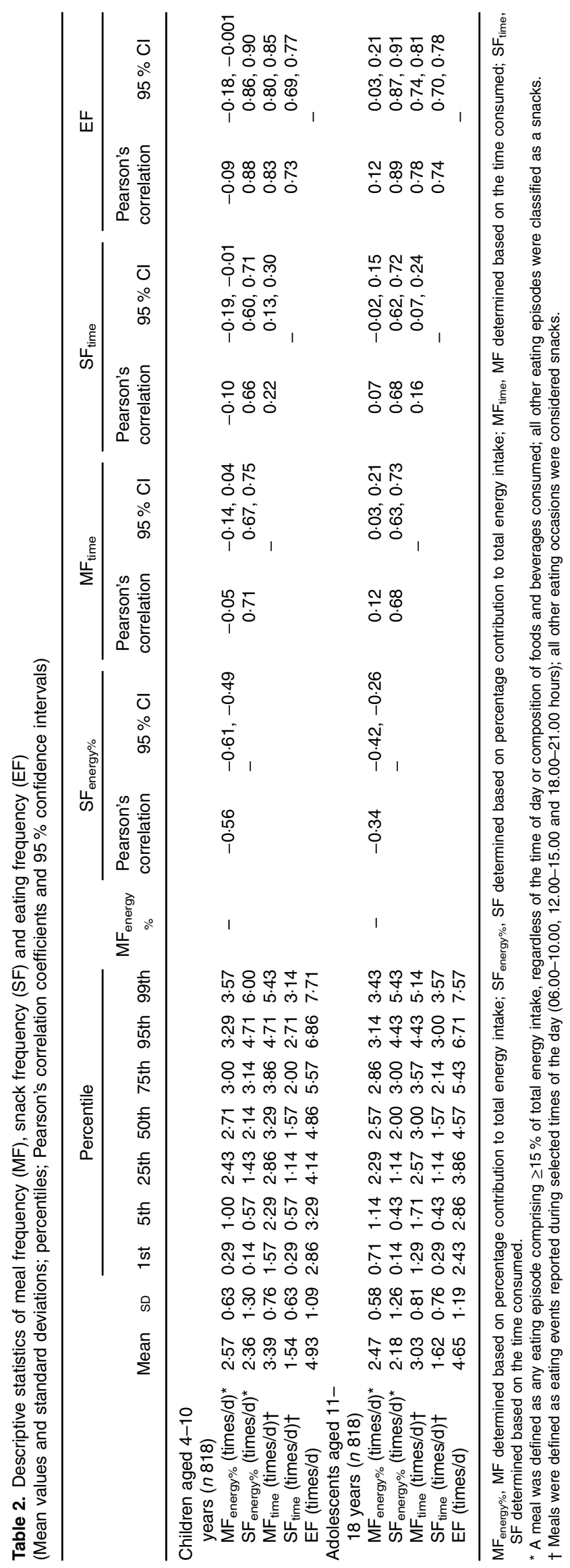




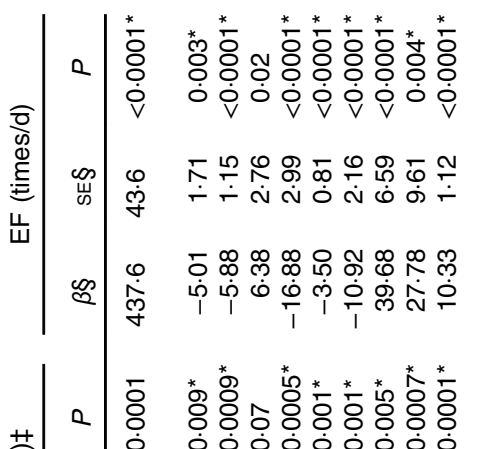

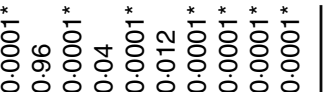

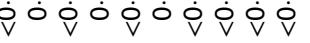

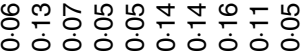

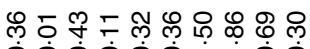
广OO

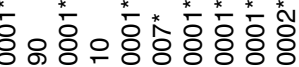

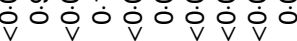

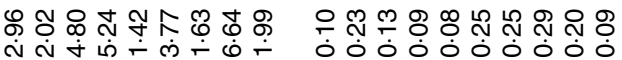

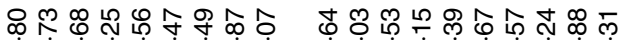
i

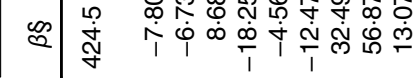

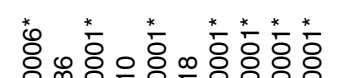

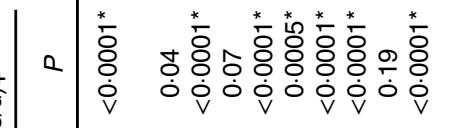

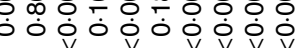

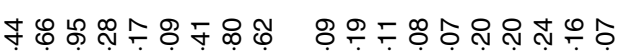

嵌

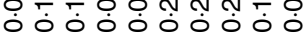

$\stackrel{4}{\Sigma}$

舟

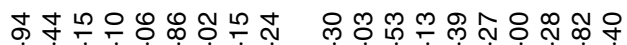

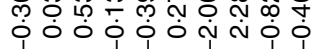

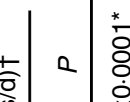

* * * * * * * * * * * *

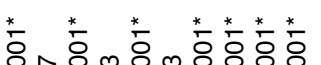
omolo

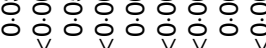

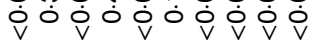

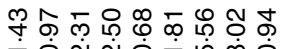

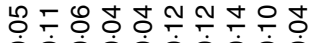

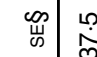

-ON

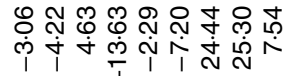

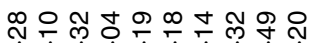

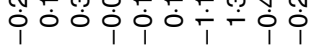

\section{ב}

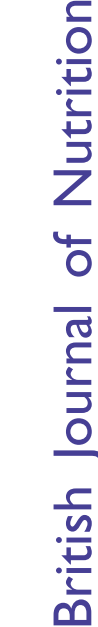

峁

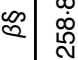

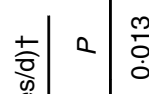

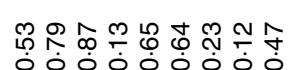

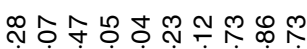

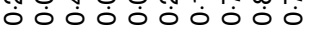

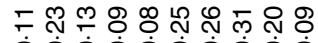

$\underset{\substack{\infty \\ \infty}}{\infty}$

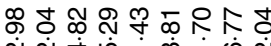

NALーME

웅 苍贷

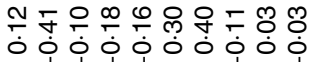

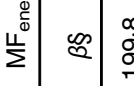

1

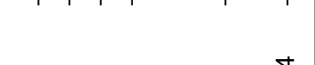

के

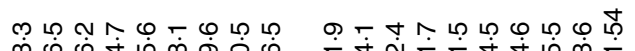

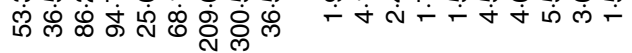

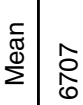

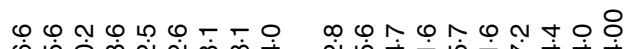

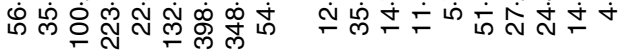

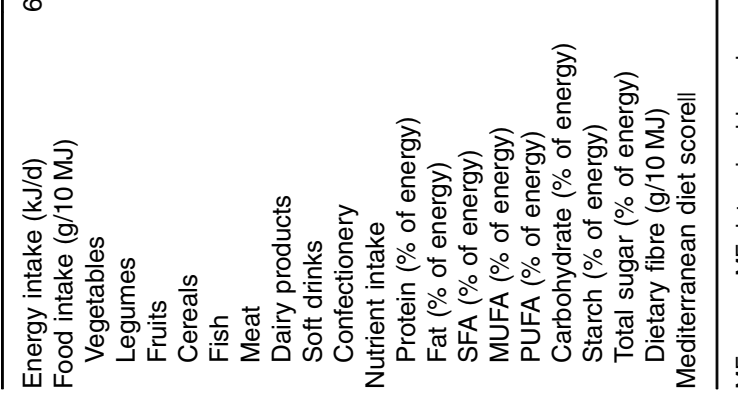

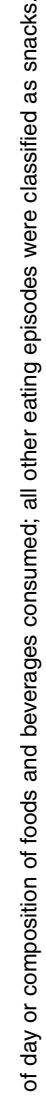

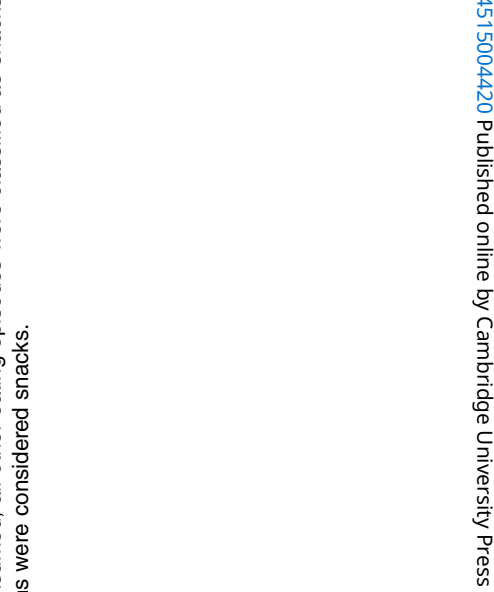




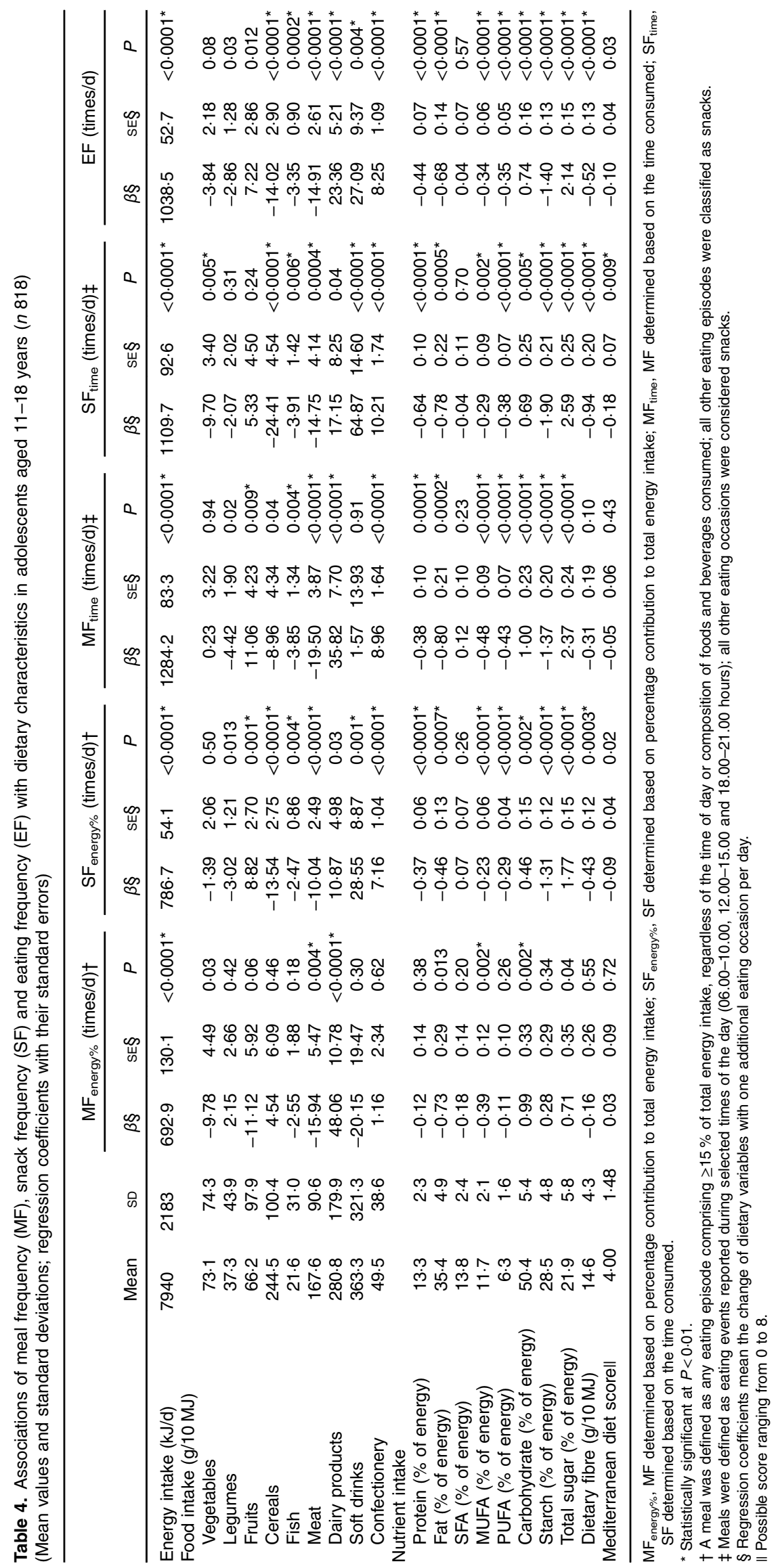


Table 5. Associations of meal frequency (MF) and snack frequency (SF) with adiposity measures† (Regression coefficients with their standard errors)

\begin{tabular}{|c|c|c|c|c|c|c|}
\hline & \multicolumn{3}{|c|}{ All subjects } & \multicolumn{3}{|c|}{ Only acceptable reporters $\ddagger$} \\
\hline & $\beta \S$ & $\mathrm{SE} \S$ & $P$ & $\beta \S$ & $\mathrm{SE} \S$ & $P$ \\
\hline Children aged $4-10$ years $(n)$ & \multicolumn{3}{|c|}{818} & \multicolumn{3}{|c|}{657} \\
\hline \multicolumn{7}{|l|}{$\mathrm{MF}_{\text {energy\% }}($ times/d)\| } \\
\hline BMI $z$ score & 0.07 & 0.06 & 0.23 & 0.01 & 0.06 & 0.85 \\
\hline \multicolumn{7}{|l|}{$\mathrm{SF}_{\text {energy\% }}($ times $/ \mathrm{d}) \|$} \\
\hline BMI $z$ score & -0.03 & 0.03 & 0.20 & -0.002 & 0.03 & 0.95 \\
\hline \multicolumn{7}{|l|}{$\mathrm{MF}_{\text {time }}($ times/d) $\boldsymbol{\uparrow}$} \\
\hline BMI $z$ score & -0.07 & 0.05 & 0.14 & 0.00 & 0.05 & 0.99 \\
\hline \multicolumn{7}{|l|}{$\mathrm{SF}_{\text {time }}($ times/d) } \\
\hline BMl $z$ score & 0.02 & 0.06 & 0.76 & 0.00 & 0.05 & 0.96 \\
\hline Adolescents aged $11-18$ years $(n)$ & & 818 & & & 387 & \\
\hline \multicolumn{7}{|l|}{$\mathrm{MF}_{\text {energy\% }}($ times/d)\| } \\
\hline BMI $z$ score & 0.09 & 0.06 & 0.18 & 0.07 & 0.09 & 0.43 \\
\hline WHtR & 0.003 & 0.004 & 0.33 & 0.003 & 0.004 & 0.50 \\
\hline \multicolumn{7}{|l|}{$\mathrm{SF}_{\text {energy\% }}($ times/d)\| } \\
\hline BMI $z$ score & 0.03 & 0.03 & 0.40 & 0.04 & 0.04 & 0.38 \\
\hline WHtR & -0.001 & 0.002 & 0.60 & -0.001 & 0.002 & 0.59 \\
\hline \multicolumn{7}{|l|}{$\mathrm{MF}_{\text {time }}($ times/d) $\boldsymbol{\uparrow}$} \\
\hline BMI $z$ score & 0.13 & 0.05 & 0.02 & 0.18 & 0.07 & $0.008^{*}$ \\
\hline $\mathrm{WHtR}$ & 0.003 & 0.003 & 0.30 & 0.004 & 0.003 & 0.23 \\
\hline \multicolumn{7}{|l|}{$\mathrm{SF}_{\text {time }}($ times/d)ף } \\
\hline BMI $z$ score & 0.00 & 0.05 & 1.00 & -0.04 & 0.07 & 0.55 \\
\hline WHtR & -0.003 & 0.003 & 0.29 & -0.005 & 0.003 & 0.11 \\
\hline
\end{tabular}

$\mathrm{MF}_{\text {energy\%, }} \mathrm{MF}$ determined based on percentage contribution to total energy intake; $\mathrm{SF}_{\text {energy\%, }} \mathrm{SF}$ determined based on percentage contribution to total energy intake; $\mathrm{MF}_{\text {time }}$, MF determined based on the time consumed; $\mathrm{SF}_{\text {time }}$, SF determined based on the time consumed; WHtR, waist:height ratio.

* Statistically significant at $P<0.01$.

$\dagger$ Adjustment was made for age (years, continuous), sex (boys or girls), social class (manual, non-manual or unclassified) and physical activity (low active, active or very active). In adolescents, further adjustment was made for ratio of energy intake:estimated energy requirement (El:EER, continuous).

$\ddagger$ Acceptable reporters were defined as subjects with El:EER 0.72-1.28.

$\S$ Regression coefficients mean the change of adiposity measures with one additional eating occasion per day.

II A meal was defined as any eating episode comprising $\geq 15 \%$ of total energy intake, regardless of the time of day or composition of foods and beverages consumed; all other eating episodes were classified as snacks.

II Meals were defined as eating events reported during selected times of the day $(06.00-10.00,12.00-15.00$ and $18.00-21.00$ hours); all other eating occasions were considered snacks.

and EF also showed positive associations with intakes of confectionery, soft drinks (except for $\mathrm{MF}_{\text {time }}$ ) and total sugar and inverse associations with intakes of fish, cereals (except for $\mathrm{MF}_{\text {time }}$ ), protein, fat, PUFA, starch and dietary fibre (except for $\mathrm{MF}_{\text {time }}$ ). There were positive associations of $\mathrm{MF}_{\text {time }}$ and $\mathrm{EF}$ with dairy products and of $\mathrm{SF}_{\text {energy\% }}$ and $\mathrm{MF}_{\text {time }}$ with fruits and an inverse association of $\mathrm{SF}_{\text {time }}$ with vegetables. Only $\mathrm{SF}_{\text {time }}$ was inversely associated with MDS. Similar results were obtained when the data for acceptable reporters were analysed separately (data not shown).

In both children and adolescents, after adjustment for age, sex, social class and physical activity (and EI:EER in adolescents), all measures of MF and SF showed no association with adiposity measures (Table 5). Similar results were obtained for those deemed to be acceptable reporters, except for the positive association between $\mathrm{MF}_{\text {time }}$ and BMI $z$ score in adolescents.

\section{Discussion}

To our knowledge, this is the first study to examine the association of different measures of MF and SF with dietary intakes and adiposity measures in young populations. In this British cross-sectional study in children and adolescents, $\mathrm{MF}_{\text {energy\%, }} \mathrm{MF}_{\text {time }}, \mathrm{SF}_{\text {energy\% }}$ and $\mathrm{SF}_{\text {time }}$ were all associated with higher EI, except for $\mathrm{MF}_{\text {energy\% }}$ in children. $\mathrm{SF}_{\text {energy\% }}$ and $\mathrm{SF}_{\text {time }}$ were associated with higher intakes of soft drinks, confectionery and total sugar, lower intakes of cereals, fish, meat, protein, PUFA, starch and dietary fibre and a lower MDS (except for $\mathrm{SF}_{\text {energy\% }}$ in adolescents). $\mathrm{MF}_{\text {time }}$, but not $\mathrm{MF}_{\text {energy\%, }}$ was associated with higher intakes of confectionery and sugar, lower intakes of fish, protein, PUFA and starch, and, only in children, a lower diet quality. All measures of MF and SF showed no association with adiposity measures in both children and adolescents. Similar results were obtained when data for subjects whose EI were deemed plausible were analysed separately. Thus, the present results demonstrated that $\mathrm{SF}_{\text {energy\%, }} \mathrm{SF}_{\text {time }}$ and $\mathrm{MF}_{\text {time, }}$, but not $\mathrm{MF}_{\text {energy\%, were similarly }}$ associated with unfavourable dietary intake patterns, suggesting that decreasing the number of small eating occasions $(<15 \%$ of total EI) regardless of the time of day may be important to improve diet quality.

Although many epidemiological studies have investigated the association between $\mathrm{EF}$ (i.e. sum of MF and SF) and adiposity measures $^{(1-20)}$, none to date have attempted to investigate the effects on MF and SF separately. In the present study, $\mathrm{MF}_{\text {time, }}$ but not $\mathrm{MF}_{\text {energy\%, }} \mathrm{SF}_{\text {energy\% }}$ and $\mathrm{SF}_{\text {time, }}$, was positively associated with BMI $z$ score (but not WHtR) in adolescents, although this association reached statistical significance only when the analysis was limited to plausible EI reporters. This is plausible given that, although all measures of MF and SF were positively associated with EI (a potential causal factor), $\mathrm{MF}_{\text {time }}$ showed the strongest association with EI in adolescents. 
Having more eating occasions with the time periods 06.00-10.00, 12.00-15.00 and 18.00-21.00 hours may be specifically detrimental to BMI $z$ score, although the results should be interpreted cautiously not only because the association did not reach statistical significance when the entire adolescent population was examined but also because of the null association for WHtR. Although there were also positive, but weaker, associations of MF and SF with EI in children, all measures of MF and SF showed no association with BMI $z$ score. Previous studies have shown that children are generally good energy compensators, although this ability declines with age ${ }^{(46)}$, which might explain the positive association in adolescents reporting plausible EI but null association in

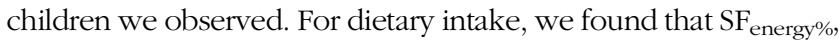
$\mathrm{SF}_{\text {time }}$ and $\mathrm{MF}_{\text {time }}$ were generally associated with unfavourable dietary intake patterns in both children and adolescents, whereas $\mathrm{MF}_{\text {energy\% }}$ showed no such associations. A previous US study showed that SF calculated on the basis of self-report, but not MF, was positively associated with diet quality (as assessed by the Healthy Eating Index) in children (aged 9-11 years) ${ }^{\text {(23) }}$. Conversely, in adolescents (aged 12-15 years) SF was inversely associated with diet quality, whereas MF showed a positive association $^{(23)}$. These discrepant findings may be, at least partly, explained by differences in the characteristics and lifestyles of the populations, definitions of MF and SF, dietary assessment methods and potential confounding factors considered.

The advantages of the present study include the use of objective and published definitions of MF and SF based on detailed dietary information obtained from a 7-d weighed dietary record, measured anthropometric data and the use of individualised measure of EER to identify EI misreporters. However, there are also several limitations. First, the cross-sectional nature of the study does not permit the assessment of causality owing to the uncertain temporality of the association. Only a prospective study would provide better understanding of the relation between MF and SF and metabolic risk factors.

We used BMI and WHtR as proxy measures of body fatness. As BMI reflects not only body fatness but also the relative length of the legs, body frame size and fat-free body mass ${ }^{(47)}$, subjects with similar BMI ( $z$ score) do not necessarily have the same amount of body fat. A more valid measure of body fat mass (e.g. dual-energy X-ray absorptiometry) may be needed for further investigation.

Another limitation of the present study is that only $61 \%$ of the eligible sample was included in the present study, although the response rate was relatively high (80\%). The subjects included in the present analysis ( $n$ 1636) differed somewhat from those excluded from the analysis ( $n$ 491). The excluded subjects were more likely to be younger and be of lower socio-economic status (all $P<0 \cdot 05$ ). However, a previous analysis concluded that there was no evidence to suggest serious non-response bias in NDNS ${ }^{(27)}$. Additionally, although we adjusted for a variety of potential confounding variables, residual confounding could not be ruled out. In particular, adjustment for physical activity may be insufficient in the analysis of children as all subjects aged $\leq 6$ years were categorised into the same category because of a lack of information. Also, we could not control for puberty status or parental weight status because of a lack of information, which may cause potential confounding by unknown or unmeasured factors

Moreover, in the present study, an eating occasion was classified as any event that provided $\geq 210 \mathrm{~kJ}$ with a minimum time interval of $>15$ min between episodes. Although this definition has been used in several previous studies ${ }^{(20,34-38)}$, some arbitrary decision (i.e. energy content and time interval) is inevitable by nature. However, there is currently no consensus about what constitutes an eating occasion, a meal or a snack. In this regard, we could not conduct the present analysis based on self-identification of eating occasions, the most common definition of meals and snacks, because of a lack of information in NDNS. Additionally, MF and SF based on time may be problematic, because eating patterns vary according to lifestyle (e.g. shift workers, individuals who consistently eat their meals at non-traditional times of day) as well as the cultural environment ${ }^{(25)}$. Furthermore, MF and SF based on energy contribution $(\geq 15$ or $<15 \%)$ was made on the basis of the US national averages of the distribution of energy from (selfdefined) meals compared with (self-defined) snacks (breakfast: $16 \%$; lunch: $25 \%$; dinner: $37 \%$; and snack: $22 \%$ from two occasions) ${ }^{(48)}$, but this may not be suitable in the present young British population. Thus, results may possibly differ on the basis of other definitions. In any case, as research explicitly examining the impact of these different definitions is limited, it is currently difficult to decide which definition might be most appropriate for meals and snacks, and as, to our knowledge, this is the only study to examine the impact of different definitions of meals and snacks on the associations between MF and SF and diet and adiposity, similar research using different definitions of meals and snacks needs to be accumulated before reaching a consensus on what defines meals and snacks.

Finally, we assessed misreporting of EI against calculated EER with the use of published equations ${ }^{(41)}$. In the absence of measured total energy expenditure, these equations with high $R^{2}$ values $(\geq 0.95)^{(41)}$ should serve as the best proxy. Nevertheless, the selection of physical activity category was based on self-report (i.e. 7 -d physical activity diary) in subjects aged $\geq 7$ years and fixed in subjects aged $\leq 6$ years, which may be susceptible to systematic error. Additionally, we do not know the sensitivity and specificity of the procedure for identifying EI misreporters used. However, even though some misclassification of subjects according to EI reporting status did occur in this study, we are confident of our conclusions, because the associations of MF and SF with dietary intakes and adiposity measures observed in the entire populations were similarly observed in acceptable reporters. Nonetheless, it should be stressed that the role of misreporting was mainly evaluated only in terms of underreporting because over-reporting occurred in such a low number of cases that no conclusions could be drawn in this regard.

In conclusion, the present cross-sectional study in Britain demonstrated that MF and SF was differentially associated with dietary intake when meals and snacks were defined on the basis of the contribution to total EI but not on the basis of time. Although all measures of MF and SF were associated with higher $\mathrm{EI}$ in children and adolescents (except for $\mathrm{MF}_{\text {energy\% }}$ in children), $\mathrm{SF}_{\text {energy\% }}$ and $\mathrm{SF}_{\text {time }}$ were associated with unfavourable dietary 
intake patterns, including higher intakes of soft drinks, confectionery and total sugar, lower intakes of cereals, fish, meat, protein, PUFA, starch and dietary fibre, and a lower MDS (except for $\mathrm{SF}_{\text {energy\% }}$ in adolescents). $\mathrm{MF}_{\text {time, }}$, but not $\mathrm{MF}_{\text {energy\%, was }}$ associated with adverse dietary profiles such as higher intakes of confectionery and sugar, lower intakes of fish, protein, PUFA and starch, and a lower MDS (only in children). Taken together, decreasing the number of small eating occasions ( $<15 \%$ of total EI) regardless of the time of day may be important to improve diet quality. However, all measures of MF and SF showed no association with adiposity measures in both children and adolescents. These findings were not influenced by misreporting of EI, as similar associations were observed not only in the entire population but also in subjects with plausible EI. Further research, particularly with a prospective design, is needed so that firm conclusions can be drawn with regard to the effect of MF and SF on dietary intakes and adiposity measures.

\section{Acknowledgements}

The authors would like to thank the anonymous reviewers for their valuable comments and suggestions to improve the quality of the manuscript.

This work was supported in part by the Grants-in-Aid for Young Scientists (B) from the Ministry of Education, Culture, Sports, Science and Technology of Japan (K. M., grant number 15K16213). The Ministry of Education, Culture, Sports, Science and Technology of Japan had no role in the design, analysis or writing of this article.

K. M. contributed to the concept and design of the study, statistical analysis, data interpretation and manuscript writing. M. B. E. L. critically reviewed the manuscript. All authors read and approved the final manuscript.

The authors declare that there are no conflicts of interest.

\section{References}

1. Ritchie LD (2012) Less frequent eating predicts greater BMI and waist circumference in female adolescents. Am J Clin Nutr 95, 290-296.

2. Keast DR, Nicklas TA \& O'Neil CE (2010) Snacking is associated with reduced risk of overweight and reduced abdominal obesity in adolescents: National Health and Nutrition Examination Survey (NHANES) 1999-2004. Am J Clin Nutr 92, 428-435.

3. Barba G, Troiano E, Russo P, et al. (2006) Total fat, fat distribution and blood pressure according to eating frequency in children living in southern Italy: the ARCA project. Int $J$ Obes (Lond) 30, 1166-1169.

4. Antonogeorgos G, Panagiotakos DB, Papadimitriou A, et al. (2012) Breakfast consumption and meal frequency interaction with childhood obesity. Pediatr Obes 7, 65-72.

5. Eloranta AM, Lindi V, Schwab U, et al. (2012) Dietary factors associated with overweight and body adiposity in Finnish children aged 6-8 years: the PANIC study. Int J Obes (Lond) 36, 950-955.

6. Franko DL, Striegel-Moore RH, Thompson D, et al. (2008) The relationship between meal frequency and body mass index in black and white adolescent girls: more is less. Int $J$ Obes (Lond) 32, 23-29.
7. Cassimos D, Sidiropoulos H, Batzios S, et al. (2011) Sociodemographic and dietary risk factors for excess weight in a Greek pediatric population living in Kavala, Northern Greece. Nutr Clin Pract 26, 186-191.

8. Mota J, Fidalgo F, Silva R, et al. (2008) Relationships between physical activity, obesity and meal frequency in adolescents. Ann Hum Biol 35, 1-10.

9. Lagiou A \& Parava M (2008) Correlates of childhood obesity in Athens, Greece. Public Health Nutr 11, 940-945.

10. Kosti RI, Panagiotakos DB, Mihas CC, et al. (2007) Dietary habits, physical activity and prevalence of overweight/obesity among adolescents in Greece: the Vyronas study. Med Sci Monit 13, CR437-CR444.

11. Neutzling MB, Taddei JA \& Gigante DP (2003) Risk factors of obesity among Brazilian adolescents: a case-control study. Public Health Nutr 6, 743-749.

12. Lioret S, Touvier M, Lafay L, et al. (2008) Are eating occasions and their energy content related to child overweight and socioeconomic status? Obesity (Silver Spring) 16, 2518-2523.

13. Toschke AM, Kuchenhoff H, Koletzko B, et al. (2005) Meal frequency and childhood obesity. Obes Res 13, 1932-1938.

14. Kontogianni MD, Farmaki AE, Vidra N, et al. (2010) Associations between lifestyle patterns and body mass index in a sample of Greek children and adolescents. J Am Diet Assoc 110, 215-221.

15. Thompson OM, Ballew C, Resnicow K, et al. (2006) Dietary pattern as a predictor of change in BMI z-score among girls. Int J Obes (Lond) 30, 176-182.

16. Jennings A, Cassidy A, van Sluijs EM, et al. (2012) Associations between eating frequency, adiposity, diet, and activity in 9-10 year old healthy-weight and centrally obese children. Obesity (Silver Spring) 20, 1462-1468.

17. Ferreira RJ \& Marques-Vidal PM (2008) Prevalence and determinants of obesity in children in public schools of Sintra, Portugal. Obesity (Silver Spring) 16, 497-500.

18. Nicklas TA, Yang SJ, Baranowski T, et al. (2003) Eating patterns and obesity in children. The Bogalusa Heart study. Am J Prev Med 25, 9-16.

19. Huang TT, Howarth NC, Lin BH, et al. (2004) Energy intake and meal portions: associations with BMI percentile in U.S. children. Obes Res 12, 1875-1885.

20. Murakami K \& Livingstone MBE (2014) Associations of eating frequency with adiposity measures, blood lipid profiles and blood pressure in British children and adolescents. Br J Nutr 111, 2176-2183.

21. McCrory MA, Howarth NC, Roberts SB, et al. (2011) Eating frequency and energy regulation in free-living adults consuming self-selected diets. J Nutr 141, 148S-153S.

22. Bellisle F, McDevitt R \& Prentice AM (1997) Meal frequency and energy balance. Br J Nutr 77, Suppl. 1, S57-S70.

23. Evans EW, Jacques PF, Dallal GE, et al. (2015) The role of eating frequency on total energy intake and diet quality in a low-income, racially diverse sample of schoolchildren. Public Health Nutr 18, 474-481.

24. Chapelot D (2011) The role of snacking in energy balance: a biobehavioral approach. J Nutr 141, 158-162.

25. Johnson GH \& Anderson GH (2010) Snacking definitions: impact on interpretation of the literature and dietary recommendations. Crit Rev Food Sci Nutr 50, 848-871.

26. Leech RM, Worsley A, Timperio A, et al. (2015) Understanding meal patterns: definitions, methodology and impact on nutrient intake and diet quality. Nutr Res Rev 28, 1-21.

27. Gregory J \& Lowe S (2000) National Diet and Nutrition Survey: Young People Aged 4 to 18 Years. Vol. 1: Report of the Diet and Nutrition. London: Stationery Office.

28. Murakami K, McCaffrey TA \& Livingstone MBE (2013) Dietary glycaemic index and glycaemic load in relation to food and 
nutrient intake and indices of body fatness in British children and adolescents. Br J Nutr 110, 1512-1523.

29. Cole TJ, Freeman JV \& Preece MA (1995) Body mass index reference curves for the UK, 1990. Arch Dis Child 73, 25-29.

30. Smithers G (1993) MAFF's nutrient databank. Nutr Food Sci 93, 16-19.

31. Food Standards Agency (2002) McCance E Widdowson's the Composition of Foods, 6th ed. Cambridge: Royal Society of Chemistry.

32. Trichopoulou A, Orfanos P, Norat T, et al. (2005) Modified Mediterranean diet and survival: EPIC-elderly prospective cohort study. BMJ 330, 991.

33. Struijk EA, Beulens JW, May AM, et al. (2014) Dietary patterns in relation to disease burden expressed in disability-adjusted life years. Am J Clin Nutr 100, 1158-1165.

34. Hartline-Grafton HL, Rose D, Johnson CC, et al. (2010) The influence of weekday eating patterns on energy intake and BMI among female elementary school personnel. Obesity (Silver Spring) 18, 736-742.

35. Mills JP, Perry CD \& Reicks M (2011) Eating frequency is associated with energy intake but not obesity in midlife women. Obesity (Silver Spring) 19, 552-559.

36. Yannakoulia M, Melistas L, Solomou E, et al. (2007) Association of eating frequency with body fatness in pre- and postmenopausal women. Obesity (Silver Spring) 15, 100-106.

37. Ma Y, Bertone ER, Stanek EJ 3rd, et al. (2003) Association between eating patterns and obesity in a free-living US adult population. Am J Epidemiol 158, 85-92.

38. Ruidavets JB, Bongard V, Bataille V, et al. (2002) Eating frequency and body fatness in middle-aged men. Int J Obes Relat Metab Disord 26, 1476-1483.
39. Duffey KJ, Pereira RA \& Popkin BM (2013) Prevalence and energy intake from snacking in Brazil: analysis of the first nationwide individual survey. Eur J Clin Nutr 67, 868-874.

40. Ainsworth BE, Haskell WL, Herrmann SD, et al. (2011) 2011 Compendium of physical activities: a second update of codes and MET values. Med Sci Sports Exerc 43, 1575-1581.

41. Institute of Medicine (2002) Dietary Reference Intakes for Energy, Carbohydrate, Fiber, Fat, Fatty Acids, Cholesterol, Protein and Amino Acids. Washington, DC: National Academies Press.

42. Rennie KL, Jebb SA, Wright A, et al. (2005) Secular trends in under-reporting in young people. Br J Nutr 93, 241-247.

43. Johnson L, Mander AP, Jones LR, et al. (2007) Is sugar-sweetened beverage consumption associated with increased fatness in children? Nutrition 23, 557-563.

44. McCaffrey TA, Rennie KL, Kerr MA, et al. (2008) Energy density of the diet and change in body fatness from childhood to adolescence; is there a relation? Am J Clin Nutr 87, 1230-1237.

45. Kelly MT, Rennie KL, Wallace JM, et al. (2009) Associations between the portion sizes of food groups consumed and measures of adiposity in the British National Diet and Nutrition Survey. Br J Nutr 101, 1413-1420.

46. Cecil JE, Palmer CN, Wrieden W, et al. (2005) Energy intakes of children after preloads: adjustment, not compensation. $\mathrm{AmJ}$ Clin Nutr 82, 302-308.

47. Prentice AM \& Jebb SA (2001) Beyond body mass index. Obes Rev 2, 141-147.

48. Kant AK \& Graubard BI (2015) 40-Year trends in meal and snack eating behaviors of American adults. J Acad Nutr Diet 115, 50-63. 